\title{
49 - Transmissão vertical natural por Hepatozoon canis em neonatos caninos. Relato de caso
}

Martins, R.R. '; Klein, R.P.'; Silveira, V.F.'; Takahira, R.K. ${ }^{2}$
Perez, R.R.'
1- Pós-graduanda da área de Clínica Médica Veterinária do programa de Pós-graduação da Faculdade de Medicina Veterinária da Universidade Estadual Paulista, Campus de Botucatu, Botucatu-SP

2-Professora assistente do Departamento de Clínica Veterinária, Laboratório Clínico Veterinário da Faculdade de Medicina Veterinária da Universidade Estadual Paulista, Campus de Botucatu, Botucatu-SP

O Hepatozoon canis é um protozoário do filo Apicomplexa, identificado por James, em 1905, na Índia. Descrito na África, Europa, Ásia e nas Américas, seus relatos são pouco freqüentes no Brasil, onde geralmente apresenta uma maior ocorrência em áreas rurais. A transmissão horizontal de $H$. canis é bem conhecida, sendo que um cão pode infectar-se através da ingestão de carrapatos (Rhipicaphalus sanguineus) contendo oocistos esporulados na sua hemocele. Por outro lado, a transmissão vertical de $H$. canis em cães não está bem caracterizada, sendo reportada, até hoje, uma única vez no Japão. O objetivo do presente trabalho é relatar a ocorrência de um caso encontrado no Canil do Hospital Veterinário da Faculdade de Medicina Veterinária e Zootecnia, UNESP de Botucatu, onde foi realizada uma seleção de cadelas prenhes para testar sua higidez para um projeto de pesquisa, em que foram realizados exames clínicos e laboratoriais. Ao exame hematológico de uma das cadelas, adulta, sem raça definida, com duas semanas de gestação foram encontrados gamontes de $H$. canis no esfregaço sangüíneo. Este animal foi encaminhado para a Maternidade da Pós-graduação, e colocado em uma sala previamente tratada com anticarrapaticida. Esta fêmea pariu 11 filhotes sendo màe e neonatos mantidos isolados de outros animais, livres de endo e ectoparasitas, e sem possibilidade de contato com carrapatos. Com 3 dias de vida os filhotes passaram a ser avaliados semanalmente através do esfregaço de sangue periférico para pesquisa de hematozoários. Aos 24 dias foram encontrados gamontes de $H$. canis em apenas um dos neonatos. Com 31 dias de vida, 8 dos 11 fillhotes já apresentavam gamontes e no $38^{\circ}$ dia de vida, toda ninhada apresentava-se infectada. Os gamontes estavam sempre presentes em monócitos, nào tendo sido encontrados em neutrófilos. No início a parasitemia era baixa, seguida de um crescente aumento no número de células parasitadas. Tanto a cadela, quanto seus filhotes não apresentaram sintomatologia clínica comum à doença. A presença prematura de gamontes de $H$. canis no sangue periférico de todos os filhotes, a partir do $24^{\circ}$ dia de idade, juntamente com as condições em que estes animais foram mantidos, sem possibilidade de contato com carrapatos, comprova a transmissão transplacentária.

\section{0 - Estudo comparativo da incidência de endoparasitoses entre gatos domésticos (Felis catus) jovens, adultos e senis no município de Vargem Grande do Sul, Estado de São Paulo}

1- Médica Veterinária Especialista na área de Patologia Clínica pela Faculdade de Medicina Veterinária das Faculdades Integradas Fundação de Ensino "Octávio Bastos"

Parasitoses são afecções causadas pela associação intima entre os seres vivos na qual um deles, chamado de parasito, se beneficia em grau variável do metabolismo de outro organismo, conhecido como hospedeiro. Foi realizado no Laboratório de Análises Clínicas do Hospital Veterinário da Fundação de Ensino "Octávio Bastos", São João da Boa Vista - SP, durante o período de setembro de 2002 a janeiro de 2003 um estudo com o objetivo de observar a incidência dos endoparasitas mais encontrados em felinos jovens, adultos e senis. Para tal, 
foram utilizadas amostras fecais de 96 animais divididos em 3 grupos: um grupo de 45 gatos jovens com até 10 meses de idade; outro, de 39 gatos adultos de 11 meses até 8 anos; por último, 12 gatos senis acima de 9 anos de idade. Todas as amostras foram submetidas a quatro técnicas coproparasitológicos: Wills, Faust, Hoffman e Safranina-azul de metileno. Foi encontrado um total de 52 animais positivos, sendo 26 gatos jovens, 20, adultos e 6 senis. No caso dos filhotes, os parasitas mais encontrados, em ordem decrescente, foram: Cystoisospora sp, 9; Giardia sp, 6; Ancylostoma sp, 4; Toxocara spp, 3; Dipylidium caninum, 3 e Sarcocystis spp, 1. Nos adultos: Giardia sp, 13; Cystoisospora spp, 8; Ancylostoma spp, 6; Toxocara spp, 6; Dipylidium caninum, 3; Sarrocystis spp, 2 e Platynosomum fastosun, 1. E nos senis: Giardia sp, 7; Cystoisospora sp, 4; Ancylostoma spp, 1 . O grande número de animais negativos provavelmente deve-se ao fato de possuir proprietário e serem possivelmente vermifugados periodicamente. $\mathrm{O}$ maior índice de positividade nos gatos jovens provavelmente deu-se devido a sua maior sensibilidade e menor imunidade. Nos grupos citados, houve maior incidência dos protozoários Cystoisospora sp e Giardia sp. Das técnicas utilizadas, a de Faust mostrou-se superior na identificação de Giardia sp; a técnica de Safranina-azul de metileno para Cryptosporidium sp; a de Hoffmann para Platynosomum fastosum e a de Wills para Ancylostoma spp e Cystoisospora sp. Conclui-se através deste estudo, a presença de um grande número de parasitose de gatos, sendo algumas consideradas zoonoses como, Ancylostoma spp, Toxacara spp, Cryptosporidium sp e Dipylidium caninum.

\section{1 - Leucemia em cão portador de Leishmaniose visceral. Relato de caso}

Roberto, T'; Maia, C.A.A.'; Lins, B.T.'; Ciarlini, P.C.'; Feitosa, M.M.'
1- Curso de Medicina Veterinária da Faculdade de Medicina Veterinária e Agrárias da Universidade Estadual Paulista, Campus de Araçatuba, Araçatuba-SP

Um animal da espécie canina, sem raça definida, macho, de seis anos de idade foi atendido no Hospital Veterinário Luiz Quintiliano de Oliveira apresentando hiporexia há 20 dias e episódios de êmese há cinco dias. Ao exame físico geral não foi constatada nenhuma alteração. À palpação abdominal percebeu-se esplenomegalia, confirmada pelo exame radiográfico.Realizou-se hemograma completo, cujo eritrograma indicou uma anemia normocítica de caráter regenerativo (eritrócitos: $2,18 \times 10^{6} / \mathrm{mL}$ volume globular: $18 \%$ ). O leucograma evidenciou leucopenia $\left(5,4 \times 10^{3} / \mathrm{mL}\right)$ por neutropenia $\left(2,39 \times 10^{3} / \mathrm{mL}\right)$, com $78 \%$ de linfócitos com atipia nuclear e citoplasmática, sendo a maioria pró-linfócitos, e apenas $9 \%$ de células blásticas. Algumas mitoses atípicas foram observadas. Diante da suspeita de leucemia, realizou-se mielograma do cão, onde foram encontradas poucas partículas hiperproliferativas, com baixa concentração de gordura, megacariocitos e série vermelha com maturação normal.. Encontrou-se ainda metamielócitos gigantes, bastonetes, porcentagem de segmentados diminuída e muitos macrófagos contendo formas amastigotas de Leishmania sp. Havia aumento do número de plasmócitos e vários linfócitos jovens atípicos (binucleados, núcleo em roseta e com distribuição aberrante da cromatina), mitoses atípicas, número de células linfocitárias menor que $15 \%$, sendo que a maioria apresentava núcleo paquicromático. Foi realizada sorologia para Leishmaniose pelo método ELISA, sendo o resultado positivo. 